\title{
Apariencia y juego. La teoría de la imitación de Walter Benjamin
}

\section{Semblance and Play. Walter Benjamin's Theory of Imitation}

\author{
José Luis Delgado Rojo \\ (Scuola Normale Superiore, Pisa - Firenze)
}

Recibido: 16/01/2015

Aceptado: 09/04/2015

\section{Resumen}

El presente trabajo analiza la teoría de la imitación desarrollada por Walter Benjamin en el célebre ensayo sobre la obra de arte. Se pretende abordar el ensayo como una nueva muestra de la "investigación sobre el origen" ya empleada en sus obras anteriores, lo cual nos permitirá esclarecer el papel privilegiado que Benjamin asigna a la "mimesis" como el "origen" que revela la ley unitaria de toda la época. El ensayo, por tanto, supera el reducido ámbito de la estética en el que ha sido tradicionalmente enmarcado y apunta a una reflexión más amplia sobre las contradicciones internas de la modernidad, respecto de la cual la mimesis señala a la vez el problema y una posible vía de salida.

Palabras clave: Benjamin, Caillois, dialéctica, Goethe, morfología, mimesis, origen.

\begin{abstract}
The following paper focuses on the theory of imitation developed by Walter Benjamin in the famous work of art essay. The essay is approached as a new sample of the "research on the origin" already used in his previous works, which will allow us to highlight the key role assigned to "mimesis" as the "origin" which discloses the unitary law of the whole age. The essay, therefore, overcomes the limited scope of aesthetics in which traditionally has been framed and aims to a wider reflection on the inner contradictions of modernity, regarding which mimesis indicates both the problem and a possible way out.
\end{abstract}

Keywords: Benjamin, Caillois, dialectics, Goethe, morphology, mimesis, origin. 


\section{La mimesis como "origen" del siglo $X X$}

El ensayo sobre la obra de arte es sin duda uno de los más célebres y citados de Walter Benjamin, aunque probablemente también uno de los más incomprendidos. Tal vez tenga que ver con ello el hecho de que habitualmente haya sido leído como un ensayo de estética, borrando así las huellas que lo unen a sus anteriores investigaciones históricas. En efecto, Benjamin recupera en el ensayo las coordenadas metodológicas de la "investigación del origen" o "historia originaria", que ya había empleado en obras tan importantes como el Origen del Trauerspiel alemán o el Passagen-Werk. Por tanto, sería necesario complementar la lectura en clave estética, que toma el ensayo como un análisis de la vanguardia artística de principios del siglo XX, con un enfoque más sensible a la peculiar filosofía de la historia que sustenta la descripción benjaminiana del arte de su época. Si Benjamin se ocupa de la situación contemporánea del arte es para leer en ella la clave de interpretación de la experiencia histórica que atraviesa la época en su conjunto. Lo que sigue a continuación es, en buena medida, un intento de mostrar la posible convergencia entre ambas perspectivas, la estética y la histórico-filosófica.

Según el modo de exposición more goetheano que había guiado sus anteriores investigaciones sobre el "origen", el ensayo sobre la obra de arte vuelve a disponer en una serie los fenómenos relevantes de una época de modo que pierdan su aparente heterogeneidad y aparezcan como variaciones de una estructura común, la cual se muestra de forma ejemplar en un determinado fenómeno particular ${ }^{1}$. Igual que la alegoría respecto al Barroco y el fetichismo de la mercancía respecto al siglo XIX, es ahora la mimesis la que funciona como cifra paradigmática de los cambios ocurridos a principios del siglo XX en esferas tan diversas como la técnica, la política, la producción artística o el régimen de percepción. La mimesis encierra el "fenómeno originario" del arte y, con él, de toda la época. De esta manera, Benjamin ofrece en el ensayo un destilado de su obra previa.

Sus diferentes trabajos sobre el "origen" constituyen entonces ligeras variaciones en torno a un método de investigación relativamente estable. Al sostener que la unidad de la reflexión benjaminiana sobre la historia está ya dada desde el inicio (o al menos desde el libro sobre el Barroco) podría parecer que estamos proyectando sobre su obra un esquema interpretativo de corte historicista, es decir, aquella concepción que combatió enérgicamente durante toda su vida. Sin embargo la unidad a la que nos referimos no es la de un "proceso" o una línea de "desarrollo", como si Benjamin se hubiera dedicado en sus obras de madurez a desarrollar el germen pre-

\footnotetext{
1 Sobre la unidad metodológica entre las investigaciones de Benjamin sobre el "origen", y sobre su deuda con la morfología goetheana, me permito remitir a mi trabajo "Benjamin y Wittgenstein. Una aproximación morfológica”, Ágora. Papeles de Filosofía, Vol. 34, No. 1, 2015, pp. 33-57.
} 
sente en sus primeras obras, formando el antes y el después las etapas de un continuo diacrónico ${ }^{2}$. Al contrario, la unidad que muestran sus obras es una unidad sincrónica o inmóvil. De la obra de Benjamin se ha dicho que es un "todo compuesto de todos y no de partes" 3 . Considerados desde este punto de vista, sus textos no se nos aparecen como "partes" de un "todo" mayor (la obra completa del autor) sino que cada uno de ellos es ya "todo", es decir, una nueva manifestación del mismo conjunto reducido de motivos. Una lectura así, que rastrea en los segmentos discontinuos que forman su producción la presencia de un núcleo invariable, se distingue netamente del esquema genético del historicismo, para el que los momentos parciales solo adquieren sentido en función de su contribución al proceso global. Por lo tanto, no se trata aquí de decidir si entre las diferentes etapas de su obra lo que domina es la continuidad o la ruptura. Ni la obra tardía desarrolla sus primeros escritos ni los abandona para emprender una nueva dirección. Ambas etapas deben considerarse, más bien, como variaciones sobre el mismo núcleo de problemas.

Por tanto, al suponer una afinidad estructural entre los trabajos de Benjamin sobre el "origen" - uno de aquellos motivos estáticos y sin desarrollo - no dejamos de atenernos a la propia concepción benjaminiana del tiempo histórico. En sus investigaciones históricas Benjamin se aleja de una exposición de tipo genético, que conecta momentos sucesivos mediante un vínculo causal, y establece en cambio un vínculo interpretativo entre tiempos remotos. De esta forma, pasado y presente son resignificados como ejemplos de un mismo modelo invariante, donde se hallan reunidos "en reposo" o "en equilibro" (im Stillstand). Esta estructura atemporal - es decir, anterior al antes y después de la historia - constituye para Benjamin el auténtico objeto de conocimiento histórico (bajo sus diferentes nombres: el "origen", la "idea" o, en los años treinta, la "imagen"). Benjamin busca en los fenómenos no las relaciones empíricas sino la verdad, no la causa sino el significado, oculto por la falsa apariencia de continuidad y revelado por el investigador mediante una disposición artificial de los hechos (la "construcción" o "montaje"). Los fragmentos que Benjamin incluye en la exposición aparecen entonces como diferentes muestras de una estructura común a épocas remotas. De esta manera, el dispositivo historiográfico benjaminiano reúne simultáneamente la ruptura (cronológica) y la continuidad

\footnotetext{
2 Si Benjamin entiende el pasado como germen del presente no es como algo pendiente de desarrollo sino, al contrario, como algo acabado e inalterable. Por ejemplo, en ¿Crisis del Darwinismo? (1929) Benjamin se apoyaba en la obra del paleontólogo Edgar Dacqué para sostener la existencia de "formas germinales" (Keimformen) o "fenómenos originarios" que no progresan evolutivamente a través de un proceso continuo sino que ya se hallan totalmente desarrolladas en su estado inicial y reaparecen luego intermitentemente en el transcurso de la historia (Gesammelte Schriften vol. IV, 1, Frankfurt am Main, Suhrkamp, 1972, pp. 534-536). En adelante citado como GS, seguido del número de volumen, sección y página. Las traducciones son mías salvo indicación de lo contrario.

3 Schweppenhäuser, H., "Zur Physiognomie eines Physiognomikers", en S. Unseld (hrsg.), Zur Aktualität Walter Benjamins, Frankfurt am Main, Suhrkamp, 1972, p. 140.
} 
(formal): el momento destructivo, que libera los fenómenos de la "falsa unidad"4 (la continuidad histórica), y el momento constructivo, dirigido a mostrar la "verdadera unidad", es decir, el arquetipo que expresa la afinidad a distancia entre épocas distintas. Este archè de la historia es precisamente lo que Benjamin designa con la categoría de "origen". Por lo tanto, no hay que ver en las diferentes investigaciones sobre el "origen" la unidad de un proceso de desarrollo sino la unidad estática de ese "todo" que aparece de forma recurrente en cada una de sus obras, ellas mismas ya "todo" y no "partes".

Una pista decisiva sobre la estrategia expositiva del ensayo sobre la obra de arte se halla en la larga nota que define la "mimesis" como el "origen" o el "fenómeno originario" de toda actividad artística.

Quien imita vuelve aparente su objeto. Dicho de otra manera: juega a ser ese objeto. Se topa entonces con la polaridad que domina en la mimesis. En la mimesis duermen, replegados el uno sobre el otro como cotiledóneos, los dos lados del arte: apariencia y juego. El dialéctico solo puede encontrar interés en esta polaridad cuando ella cumple un papel histórico. ${ }^{5}$

La mención al "cotiledóneo" (Keimblätter) no es aquí casual, ya que el cotiledóneo u hoja de dos miembros era precisamente la estructura elemental que Goethe había empleado en Die Metamorphose der Pflanzen para mostrar el invariante formal del resto de órganos de la planta 6 . Como las dos hojas del cotiledóneo, apariencia y juego forman los dos polos de la mimesis, el "origen" en el que Benjamin reconoce el principio unitario de los fenómenos que pueblan las primeras décadas del siglo XX. Este es el "papel histórico" que cumple la mimesis: expresar en un caso particular la ley válida para toda una época.

La mimesis presenta, pues, dos polos opuestos. Por un lado, imitar significa reproducir el aspecto exterior del objeto en una materia diferente, "el cuerpo mismo

\footnotetext{
4 GS I, 1, p. 213.

5 GS VII, 1, pp. 367-368. Esta nota decisiva se halla únicamente en la segunda versión del ensayo, publicada por primera vez en 1989. Sobre la desventura editorial de la segunda versión, que ha condicionado la recepción del ensayo, véase Desideri, F., "I Modern Times di Benjamin", en Id. (ed.), L'opera d'arte nell'epoca della sua riproducibilità tecnica. Tre versioni (1936-39), Roma, Donzelli, 2012, pp. VII-XLV.

6 La primera sección se titulaba precisamente "De los cotiledóneos" ("Von den Samenblättern", en Goethes Werke. Bd XIII, Hamburg, Wegner, 1960, pp. 66-69). Los cotiledóneos "son casi siempre dobles" y "las hojas de este primer nodo son a menudo simétricas (y opuestas)" (§16). Goethe reconoce en el cotiledóneo la estructura polar que, con diferentes variaciones, se halla en todos los estadios de desarrollo de la planta. Benjamin vuelve a hacer referencia a los estudios botánicos de Goethe en el Passagen-Werk, donde sostiene que el "origen" del siglo XIX debe ser expuesto "como la hoja despliega a partir de sí misma todo el reino del mundo vegetal empírico" (GS V, 1, p. 577 [N2a, 4]).
} 
de quien imita" 7 , sin que por ello se vea amenazada la interioridad del imitador. Lo típico del polo "juego" es la relativa desconexión entre el poder interno del objeto imitado y su corteza externa, que puede ser reproducida o imitada en ausencia del primero. Pero la imitación no es solo un mero representar algo (juego) sino también un ser aquello que representa (apariencia): el imitador, al adoptar los rasgos externos del objeto imitado, se transforma en ello internamente. Debido al vínculo rígido que une interior y exterior, el imitador, al reproducir la apariencia externa del original, se apropia también de su esencia interior. Entonces la apariencia sensible ya no es un mero envoltorio externo sino la manifestación inmediata de un principio espiritual ${ }^{8}$.

Con los dos polos de la mimesis Benjamin distingue dos modos distintos de relación entre una copia sensible y un modelo inteligible: la unidad inmediata y la relativa separación. En el fondo, se trata de la misma polaridad que se hallaba tras los fenómenos de "origen" empleados en sus anteriores investigaciones. Por ejemplo, el libro sobre el Barroco definía el funcionamiento de la alegoría según una "dialéctica de convención y expresión". En esta polaridad Benjamin detectaba la "transposición a ámbito semiótico"10 (es decir, al ámbito de las relaciones entre signo y significado) del conflicto más general que afectaba a la experiencia histórica del Barroco, dividida entre la asunción desencantada de la inmanencia terrenal y la aspiración a alguna forma de trascendencia11. Resulta revelador que, ya entonces, para caracterizar las dos posibilidades de resolución dramática de los Trauerspiele

\footnotetext{
7 GS VII, 1, p. 368.

8 Esta oposición se asemeja a la distinción propuesta por Elias Canetti entre "simulación" y "metamorfosis". Mientras que la "simulación" concierne exclusivamente al aspecto externo del objeto, sin afectar al núcleo íntimo del imitador, la "metamorfosis" elimina cualquier distancia, transformando al imitador en aquello que imita (Masse und Macht, Hamburg, Claassen, 1960, pp. 425-426). Sobre la distinción benjaminiana entre los dos tipos de mimesis - la "relación con la alteridad" y la "identificación-asimilación" - véase Desideri, F., "The mimetic bond: Benjamin and the question of technology", en A. Benjamin (ed.), Walter Benjamin and Art, London, Continuum, 2005, p. 115. Sobre los dos significados opuestos de la mimesis en el marco general de su obra véase Lang, T., Mimetisches oder semiologisches Vermögen? Studien zu Walter Benjamins Begriff der Mimesis, Göttingen, Vandenhoeck \& Ruprecht, 1998, pp. 107-111.

9 GS I, 1, p. 351.

10 GS I, 1, p. 342.

11 El mismo conflicto presente en la alegoría se repite a escala en cada una de las facetas que componen el fenómeno Trauerspiel: la "antítesis" de catástrofe y restauración en la noción de soberanía, la "polaridad" del mártir y el tirano en el personaje principal del rey y la "dialéctica" entre gravedad y furia del temperamento melancólico. Sobre la estructura polar del libro véase Menninghaus, W., Walter Benjamins Theorie der Sprachmagie, Frankfurt am Main, Suhrkamp, 1980, p. 97 ss. En cambio, sobre la deuda de la estructura opositiva con la morfología goetheana véase Pinotti, A., "'Lo studio degli stremi'. Benjamin morfologo tra Warburg e Goethe”, en Id. (ed.), Giochi per melanconici. Sull 'Origine del dramma barocco tedesco'di Walter Benjamin, Milano, Mimesis, 2003, pp. 195-231.
} 
Benjamin hablara de la "reflexión de juego y apariencia"12, donde la metáfora óptica de la "reflexión" entre dos espejos enfrentados expresaba precisamente la idea de complementariedad o polaridad entre dos extremos opuestos, a saber: juego y apariencia 13 . Por tanto, la polarización del desenlace de los dramas - entre la "maquinación" lúdica del teatro español y la "espacialización del tiempo" en el teatro alemán ${ }^{14}$ - repite a otra escala la dialéctica de convención y expresión presente en la alegoría.

De forma análoga, en el Passagen-Werk Benjamin reformula el fenómeno del fetichismo de la mercancía en los mismos términos que la alegoría. Como revela una lectura en filigrana de las citas de Marx recogidas en la sección X, Benjamin entreve en la definición marxiana del fetichismo la transfiguración de la "convención social" que une valor de uso y valor de cambio en la "expresión de valor"15, es decir, una relación en la que el valor de cambio aparece como emanación de la esencia abstracta del objeto. Marx se refiere a esta relación expresiva como una "encarnación"16, evidenciando así la unión "mística" que tiene lugar en el cuerpo de la mercancía entre una materia sensible (el valor de uso) y un principio inteligible (el valor de cambio). De esta forma, Benjamin advierte en los productos culturales del siglo XIX una sorprendente afinidad con la tensión barroca entre convención y expresión, el desencanto profano y la reconciliación con la trascendencia. Las cosas se espiritualizan con nuevos significados y valores en la misma medida en que se vacían como resultado del desarrollo capitalista. Nuevamente nos encontramos aquí con la polaridad entre la "apariencia"17, la unidad mística que tiene lugar en el cuerpo de la mercancía, y la "falta de apariencia"18 o el "juego"19, que aluden a la pérdida de la totalidad simbólica (en la poesía alegórica de Baudelaire o en la concepción de la técnica en Fourier).

\footnotetext{
12 GS I, 1, p. 261.

15 GS V, 2, p. 808 (X4a, 1).

16 GS V, 2, p. $806(\mathrm{X} 4,1)$.

17 GS V, 1, p. 55.

18 GS V, 1, p. 421.

19 GS V, 2, p. 813.
}

13 La misma metáfora aparece en el Passagen-Werk para caracterizar la polaridad de progreso y eterno retorno, es decir, el correlato para el siglo XIX de la experiencia barroca de simultánea elevación y devaluación del mundo profano: "la apariencia de novedad se refleja, como un espejo en otro, en la apariencia de lo siempre igual" (GS V, 1, p. 55).

14 GS I, 1, pp. 260-263. La "maquinación" designa la intervención final de un Deus ex machina o sucedáneo de trascendencia que, como resultado de un artificio artístico, no hace más que reafirmar el carácter desencantado de la esfera profana. En cambio, la "espacialización del tiempo" supone el intento desesperado por regresar al estado atemporal de la "creación", donde el ser se hallaba reconciliado con la trascendencia. Esta faceta polar del Trauerspiel ha pasado inadvertida incluso a los intérpretes más atentos a la estructura polar de la obra, como Menninghaus o Pinotti. 
La misma oposición, si bien declinada con otros términos, es reconocible en Sobre algunos motivos en Baudelaire (1939). Para exponer las nuevas formas de experiencia urbana que emergen entre los siglos XIX y XX Benjamin se sirve de Baudelaire, en quien detecta la expresión ejemplar de aquella polaridad que fractura internamente las manifestaciones culturales del siglo XIX: entre spleen e ideal20, melancolía y espiritualización 21 . De acuerdo con el método que se basa en el "retorno de los motivos"22 (ya anunciado y llevado a la práctica en el libro sobre el Barroco) Benjamin traza un perfil de Baudelaire mediante la exposición de algunos "motivos" de su obra. Este procedimiento pretende hacer visible la unidad de fondo entre ellos, en tanto que variaciones de un único motivo central: la oposición entre la fragmentación de la experiencia y la aspiración a una unidad orgánica (spleen e ideal) que define la experiencia en la gran ciudad. El ensayo, por tanto, expone su objeto por medio de una serie de polaridades (experiencia / vivencia, memoria / consciencia, memoria involuntaria / voluntaria), las cuales encuentran su clave de inteligibilidad en la última parte del ensayo, en la que se expone la tensión interna que atraviesa la obra de Baudelaire ${ }^{23}$. Como el hombre barroco, Baudelaire vacila entre los dos polos de la catástrofe y la restauración ${ }^{24}$ : entre la experiencia alegórica de una liquidación de la trascendencia y el intento desesperado de su recuperación. Si, por un lado, su mirada melancólica levanta acta del "mero estado de naturaleza" 25 en el que recae una existencia privada de gracia y extraña al hombre, por otro lado sueña con "una existencia más pura, más inocente y espiritual" 26 , ajena a cualquier componenda con la corrupta esfera mundana.

En definitiva, la oposición entre "apariencia" y "juego" recorre transversalmente las investigaciones de Benjamin sobre el "origen", designando siempre dos modos opuestos de relación entre términos, si bien en el ensayo sobre la obra de arte los términos involucrados son ahora copia y modelo, y no signo y significado como en la alegoría - o valor de uso y valor de cambio - como en el fetichismo de la mercancía. En la mimesis es el cuerpo de quien imita el que funciona como signo, convencional o expresivo, del significado mágico del objeto imitado.

\footnotetext{
20 GS V, 1, p. 72.

21 GS I, 2, p. 657.

22 GS I, 1, p. 212.

23 Josef Fürnkäs ha visto en la tensión entre spleen y aura la "oposición fundamental" que domina las "analogías estructurales" entre las "parejas de opuestos antitéticos" recogidas en el ensayo: la trama orgánica de la experiencia y la intermitencia de la vivencia o el shock, el sistema de memoria y consciencia (conservación y destrucción) en la teoría psíquica de Freud, la oposición entre memoria involuntaria y voluntaria en Proust, o finalmente el valor de culto de las correspondances y la destrucción alegórica en la obra de Baudelaire (cfr. "Aura", en M. Opitz und E. Wizisla (hrsg.), Benjamins Begriffe. Bd. I, Frankfurt am Main, Suhrkamp, 2000, pp. 130-140).

24 GS I, 1, p. 246.

25 GS I, 2, p. 643.

26 GS I, 2, p. 680 (Zentralpark).
} 
La polaridad de la mimesis resulta asimismo reconocible en sus trabajos contemporáneos sobre el lenguaje: el ensayo sobre la facultad mimética (1933) y la reseña Problemas de sociología del lenguaje (1935). En ellos Benjamin persigue el "origen" del lenguaje hasta el momento de su surgimiento empírico: el estadio mimético, donde el signo se asemeja al referente. Sin embargo, lo que parecía una exposición de la evolución del lenguaje desde un estadio mimético (unidad expresiva) hasta uno convencional (separación) se convierte en una descripción de la reunión sincrónica de los dos polos. En la reseña de 1935, por ejemplo, Benjamin reconoce en algunos de los autores reseñados una indistinción entre los dos estadios presente desde el inicio de la evolución ${ }^{27}$. En el ensayo sobre la facultad mimética, en cambio, la coexistencia de los dos polos tiene lugar no al inicio sino al término del proceso histórico, con la "fusión" 28 de los "dos componentes" del lenguaje: lo "semiótico" y lo "mimético".

El origen mimético del lenguaje adopta en estos trabajos dos sentidos distintos: un sentido empírico - como inicio de la serie cronológica - y un sentido ideal como modelo o prototipo de las posibilidades históricas del presente ${ }^{29}$. Algo similar sucede en el ensayo sobre la obra de arte, donde los dos lados de la mimesis hacen referencia tanto al inicio inmemorial de la actividad artística como a la estructura que predefine las posibilidades del arte contemporáneo. No debe extrañar entonces que Benjamin exponga los multiformes fenómenos de la época mediante una serie de polaridades ${ }^{30}$, dado que el objetivo de la exposición es precisamente que aparezcan ante la mirada sinóptica del lector como variaciones de la estructura polar de la mimesis.

Entre las polaridades que forman la exposición destacan sobre todo dos: primera/segunda técnica y valor de culto/valor de exposición. Con ellas Benjamin describe, respectivamente, los fenómenos de la base (técnica) y la superestructura

\footnotetext{
27 Es el caso de Karl Bühler, que describe la "gramática pura" (sincrónica) de las funciones lingüísticas (GS III, pp. 468-470), o de la investigación con animales, dirigida a la "fijación del punto geométrico en el que el lenguaje, en la intersección de la coordenadas de la inteligencia y del gesto (manual o acústico), tiene su origen" (GS III, p. 473).

28 GS II, 1, p. 213.

29 Sobre la oscilación ambigua entre los dos sentidos del "origen" véase Mosès, S., "L'idée d'origine chez Walter Benjamin", en H. Wismann (ed.), Walter Benjamin et Paris. Colloque international 2729 juin 1983, Paris, Éditions du Cerf, 1986, pp. 809-810.

30 Sobre la exposición "dialéctica" o por medio de polaridades que caracteriza el ensayo véase Lindner, B., "Das Kunstwerk im Zeitalter seiner technischen Reproduzierbarkeit", en Id. (hrsg.), Benjamin Handbuch. Leben - Werk - Wirkung, Stuttgart, Metzler, 2011, pp. 247-248; Hansen, M. B., Cinema and experience. Siegfried Kracauer, Walter Benjamin and Theodor W. Adorno, Berkeley, University of California Press, 2012, pp. 80-82. Aunque ambos autores han identificado la serie de oposiciones que recorren el ensayo, no han señalado el objetivo de este peculiar procedimiento, que es el de mostrar la forma común a todas ellas, explicitada de manera eminente por la polaridad de la mimesis.
} 
(artística). Por tanto, al mostrar la afinidad estructural entre la técnica y el arte, el ensayo cumple el propósito formulado en el Passagen-Werk de describir la relación entre ambos niveles en los términos de un vínculo de "expresión"31 (y no de una "génesis" causal, a la manera de la teoría marxista del reflejo). La base y la superestructura aparecen entonces como variaciones del "origen", es decir, la mimesis como verdadero Leitmotiv de la época.

\section{La polaridad de primera y segunda técnica}

Mediante la oposición entre "primera" y "segunda técnica" Benjamin calca la polaridad de la mimesis sobre los fenómenos de la infraestructura. Los primeros objetos técnicos surgieron de una imitación de la naturaleza que estaba "al servicio de la magia"32. Benjamin alude al tipo de imitación de la magia mimética o simpática, la práctica ritual que transfiere las propiedades de un objeto a otro por medio de su semejanza ${ }^{33}$. Esta práctica se basa en aquella relación entre copia y modelo que Benjamin denomina "apariencia", dado que para que la imitación sea capaz de apropiarse del poder eficaz de un objeto debe presuponer un vínculo indisoluble entre el aspecto externo del objeto y su esencia interior, de modo que reproducir el primero y capturar la segunda sean uno y el mismo gesto. La imitación mágica, como la "apariencia", no distingue entre parecer algo y ser algo.

Pero la magia no representa para Benjamin el estadio arcaico y ya superado de la técnica moderna sino su verdadero principio de funcionamiento ${ }^{34}$. La equiparación de la técnica moderna con la magia mimética (bajo el rótulo común de "primera técnica") podría parecer algo superficial ya que, si bien es cierto que ambas tie-

\footnotetext{
${ }^{31}$ GS V, 1, p. 573-574 (N1a, 6). Para ilustrar esta relación de "expresión" Benjamin remite al modo según el cual el "fenómeno originario" de Goethe revela la estructura común a un campo de fenómenos. 32 GS VII, 1, p. 358.

33 La magia simpática había sido analizada por James G. Frazer en La rama dorada (cap. 3, "Magia simpática"), aunque su enfoque intelectualista, que describe la magia como un sistema de pensamiento, será criticado por Marcel Mauss, quien estudia la magia como una práctica social. Para Mauss la magia se compone de actos "eminentemente eficaces, son creadores, hacen [...] se les denomina mágicos por su misma eficacia" ("Esbozo de una teoría general de la magia", en Sociología y Antropología, Madrid, Tecnos, 1979, p. 50). A diferencia de la técnica moderna, la eficacia mágica no se transmite causalmente sino por medio de las "leyes de simpatía": contigüidad, semejanza y contraste (p. 87). Más adelante Roger Caillois, que había sido alumno de Mauss, menciona al maestro en sus trabajos sobre el mimetismo escritos entre 1934 y 1935, donde define la "magia mimética" a partir de las leyes subjetivas de asociación: contigüidad, semejanza y contraste ("Mimétisme et Psychasthénie légendaire", en Le mythe et l'homme, Paris, Gallimard, 2012, pp. 106-107).

34 La comprensión de la técnica moderna como superación racional de la técnica mágica es un topos común en antropología, desde Marcel Mauss (op. cit., p. 148) hasta Arnold Gehlen ("Die Seele im technischen Zeitalter", en Gesamtausgabe. Band 6, Frankfurt am Main, Klostermann, 2004, p. 13).
} 
nen por objetivo la producción de efectos prácticos, en el fondo cada una presupone una relación hombre-naturaleza totalmente diferente. Mientras que mediante la técnica mágica el hombre se somete al logos que anima la naturaleza, la técnica moderna forma parte de un proyecto prometeico de "dominio de la naturaleza" 35 , que subordina el mundo desencantado a una medida humana. Por tanto, si la magia integra al hombre en la gran cadena del ser, la técnica moderna en cambio es una manifestación del antagonismo que enfrenta al hombre con la naturaleza. ¿Qué es entonces lo que permite a Benjamin identificar la técnica más arcaica y la más moderna? Pues precisamente el tipo de imitación denominado "apariencia".

En la antigüedad la fuente de normatividad residía en la naturaleza exterior, que proporcionaba al sujeto el modelo de su acción. En cambio, con la modernidad la fuente de normatividad se traslada al sujeto y el mundo exterior se convierte en materia dócil para realizar los proyectos del yo. Contra la concepción tradicional, que ve en la aparición de la subjetividad moderna una ruptura con el paradigma de la imitación ${ }^{36}$, Benjamin ve en la expresividad moderna no lo contrario de la imitación antigua sino una mera variante suya, una especie de imitación inversa que intercambia la posición relativa de la copia y el modelo pero conserva intacto el nexo entre ambos. La modernidad invierte el esquema premoderno, de forma que el yo se convierte en modelo y las manifestaciones del mundo exterior en sus copias, pero mantiene el propio nexo modelo-copia, es decir, la "apariencia", la absorción simbólica de lo real bajo un principio normativo racional (ya sea el logos de la naturaleza o el del sujeto).

Con la noción de "primera técnica" Benjamin prosigue la crítica realizada en el Passagen-Werk a la concepción dominante de la técnica en el siglo XIX, la "explotación de la naturaleza" 37 , en la que detecta no la escisión sujeto-objeto sino, al contrario, una muestra de "lo creativo", es decir, la proyección expresiva del yo sobre las cosas. Esta expresividad no es más que el equivalente moderno de la participación arcaica del hombre con la virtud mágica de la naturaleza, como lo muestra el hecho de que Benjamin, apoyándose en Marx, describa la técnica demiúrgica del siglo XIX como una "fuerza creadora sobrenatural" 38 que se plasma sobre la naturaleza inerte para conferir valor a sus productos. La técnica moderna proporciona el modelo al que la naturaleza debe adecuarse en tanto que copia (es decir, materia valorizada por el trabajo humano).

Si la "primera técnica" designa la manifestación sensible de una fuerza inmediatamente vinculante (ya sea el logos mágico o el logos técnico), en cambio la

\footnotetext{
35 GS VII, 1, p. 359.

36 Una buen compendio de esta concepción se encuentra en la "historia de la imitación" descrita por Javier Gomà en Imitación y experiencia, Barcelona, Crítica, 2005 (Segunda parte, pp. 223-258).

37 GS V, 1, pp. 455-456 (J75, 2).

38 GS V, 2, p. $808(X 5,1)$.
} 
"segunda técnica" rompe con esta unidad expresiva e introduce una relativa separación entre el modelo y la copia: no el "rigor" de la apariencia sino la "no vinculabilidad"39 del juego; no el "dominio de la naturaleza" sino la "distancia de la naturaleza" 40 . La copia ya no es la expresión inmediata del modelo sino que entre ambos existe un cierto margen de variación. El trabajo técnico concebido según el patrón del juego no prescribe un modelo dado a la naturaleza sino que existen diferentes modos de acoplar la capacidad productiva de la técnica con los recursos presentes en la naturaleza. Y esos acoplamientos contingentes dependerán, como en Marx, de la organización social del trabajo. Por tanto, a la creatividad autónoma de la técnica (expresión) Benjamin opone la mediación social entre técnica y naturaleza (convención). Como diría Mauss, la eficacia técnica no es "analítica" (algo dado) sino "sintética"41 (un producto social).

\section{La polaridad de culto y exposición}

Benjamin emplea la polaridad de la mimesis no solo para describir el ámbito de la técnica sino también el ámbito supraestructural del arte, que se halla fracturado por un conflicto entre el arte "cultual" y el arte "expositivo". Como veremos, esta polaridad refleja nuevamente dos modos opuestos de relación modelo-copia. Para exponer esta oposición Benjamin se apoya en la ambigüedad presente en la noción de "aura"42. El término remite al aura velificans ("velo agitado por la brisa"), un recurso artístico de la iconografía latina que consistía en representar la figura femenina como fuente de una emanación aérea solo visible a través de las ondulaciones de su atuendo. Posteriormente, el velo agitado por el aura de la figura se convertiría en signo convencional del elevado rango de las figuras representadas, la "divinidad, nobleza y lejanía de personas pertenecientes a una esfera superior" 43. Benjamin hace un uso ambivalente de la metáfora aérea del "aura", ya que si, por un lado, alude al soplo de vida sobrenatural que anima las criaturas profanas, por otro lado, representa también su polo opuesto, la intangibilidad de un modelo que nunca alcanza una manifestación integral en ninguna de sus copias sensibles.

39 GS VII, 1, p. 359.

40 ibidem.

${ }^{41}$ Son los términos que usa Mauss para describir el condicionamiento social de la práctica mágica (op. cit., pp. 135-136).

42 Sobre la "ambigüedad" del aura véase Fürnkäs, J., op. cit., pp. 112-116; Lindner, B., "Benjamins Aurakonzeption: Anthropologie und Technik, Bild und Text”, en U. Steiner (hrsg.), Walter Benjamin 1892 - 1940. Zum 100. Geburtstag, Bern, Lang, 1992, p. 232; Stoessel, M., Aura. Das vergessene Menschliche, München, Hanser, 1983, pp. 45-46.

43 Assmann, A. y J., "Air from other Planets Blowing”, en H. U. Gumbrecht and M. Marrinan (ed.), Mapping Benjamin. The work of art in the digital age, Stanford, Stanford University Press, 2003, pp. 153-154. 
El aura hace referencia, en primer lugar, a la concepción de la obra de arte como inmediata expresión sensible de lo inteligible, lo que los románticos llamaban "belleza", "bella apariencia" o simplemente "apariencia"44. Este momento de unidad simbólica alcanza su formulación canónica en la estética de Goethe, para quien "lo bello no es el velo ni el objeto velado sino el objeto en su velo"45. Estas palabras son una autocita del ensayo sobre las Afinidades electivas, donde Benjamin había usado la metáfora aérea del velo para criticar la concepción estética de Goethe y desarrollar una posición opuesta. Contra la identidad mítica entre el "objeto" suprasensible y su "velo" sensible, Benjamin elabora una dialéctica entre el "velo" y lo "velado" en virtud de la cual la superficie sensible de la obra muestra y a la vez custodia su secreto 46 . El resto "inexpresivo" de la belleza, que impide una coincidencia exhaustiva con su encarnación sensible, se opone a la unificación entre esferas propia de la "bella apariencia" 47 .

Paradójicamente, en el ensayo sobre la obra de arte el "aura" designa no solo la "apariencia" sino también su polo opuesto, el carácter "inexpresivo" de lo bello. Así, por ejemplo, en un célebre pasaje Benjamin define el aura como sigue:

reposando en una tarde de verano, seguir la línea montañosa en el horizonte o una rama que echa su sombra sobre aquel que reposa, eso quiere decir respirar el aura de esas montañas, de esta rama. 48

El aura hace aquí referencia a una dimensión trascendente de los objetos que no comparece nunca de forma directa sino lateralmente, a través de fenómenos como el "horizonte" o la "sombra", es decir, un "velo" sensible que transparenta el "objeto" suprasensible pero, a la vez, lo preserva de un total "desvelamiento" (la aprehensión inmediata mediante la vista o el tacto). Por eso el aura solo se puede "respirar", como le corresponde según su inaferrable consistencia aérea ${ }^{49}$.

$44 \mathrm{La}$ "apariencia" es una de las categorías principales de la estética romántica, que concibe la obra de arte como vehículo sensible del absoluto, lo invisible hecho visible (Mosès, S., "Walter Benjamin et le romantisme allemand", Europe, n. 1008, avril 2013, pp. 62-63).

45 GS VII, 1, p. 352.

46 GS I, 1, pp. 194-196.

47 Menninghaus sostiene que existe una "relación de polaridad" entre la "apariencia" y los elementos críticos que Benjamin dirige contra ella como, por ejemplo, "lo inexpresivo" ("Das Ausdrucklose: Walter Benjamins Metamorphosen der Bilderlosigkeit", en I. und K. Scheuerman (hrsg.), Für Walter Benjamin. Dokumente, Essays und ein Entwurf, Frankfurt am Main, Suhrkamp, 1992, pp. 173-175). En este sentido, la oposición presente en el ensayo sobre las Afinidades electivas entre la expresividad total y el resto inexpresivo de lo bello (unidad y separación entre lo ideal y lo sensible) prefigura la polaridad de apariencia y juego del ensayo sobre la obra de arte.

48 GS VII, 1, p. 355.

49 La metáfora aérea aparece también en el Passagen-Werk para definir el carácter "inexpresivo" o "inintencional" de la verdad de los fenómenos históricos que, contra las ilusiones del positivismo, no 
El aura parece designar entonces dos cosas opuestas. La saturación semántica de lo sensible y la alteridad del significado respecto cualquiera de sus manifestaciones empíricas. Por tanto, reproduce a otro nivel la oposición elemental entre los dos polos de la mimesis: la plena expresión del modelo ideal en una copia sensible o la autonomía relativa del modelo, que no se agota en ninguna de sus traducciones empíricas.

La misma ambivalencia del aura afecta a la producción artística, dividida entre un arte "cultual" y un arte "expositivo". Los nuevos medios de representación (como la fotografía o el cine) inducen un modo de recepción que convierte la realidad en una obra de arte "aurática", es decir, la plena traducción sensible de un principio espiritual. La "estetización" de la realidad señalada por Benjamin alude precisamente a esta transferencia del carácter "aurático" de la obra de arte a la realidad social, que pasa a ser contemplada como la copia visible de un modelo invisible. En este sentido, la realización del arte en la vida cotidiana, una aspiración utópica de las vanguardias artísticas del siglo XX, será cumplida paradójicamente por el fascismo, que pone las técnicas más avanzadas al servicio de la experiencia más antigua: la identificación del hombre con la realidad, que aparece como expresión de su ser íntimo. Así, el arte repite con la "segunda naturaleza" de carácter técnico la proyección expresiva de la "primera técnica" respecto a la naturaleza.

La "estetización" de la realidad es el correlato para el siglo XX de la "fantasmagoría" que Benjamin había detectado en la superestructura cultural del siglo anterior. El Passagen-Werk había puesto el foco sobre la transformación de la esfera pública del siglo XIX en un espacio expresivo, en el que tanto los productos como las conductas aparecían cargados con contenidos procedentes de la intimidad del yo (convicciones, valores y deseos individuales). En un intento desesperado por insuflar un poco de calidez a un mundo cada vez más frío e impersonal, la época reaccionó no solo haciendo del interièur burgués un refugio sino, lo que es más peligroso, haciendo del mundo exterior un interior ampliado, en el que cualquier aparición se transformaba inmediatamente en la expresión de significados personales ${ }^{50}$.

puede nunca ser conocido de una vez por todas. Véanse, por ejemplo, las referencias al "viento del absoluto" (GS V, 1, 591 [N9, 3]) o "el viento de la historia" (GS V, 1, 591 [N9, 6]) que es capturado indirectamente por las "velas" que levanta el historiador (es decir, la disposición material de los hechos en la obra historiográfica, que a la vez capta su verdad y la preserva de toda captación); o también la mención al "soplo de aire" que emana de los hechos del pasado (GS I, 2, p. 693 [tesis II]).

50 El objetivo de Benjamin al describir la extensión del fetichismo de la mercancía a los productos culturales del siglo XIX no es criticar el vaciamiento y la falta de valores sino, al contrario, su proliferación incontrolable, el rellenado artificial de las cosas con plusvalores personales: no la "mercantilización" de la cultura sino la "espiritualización" de la mercancía (Markus, G., "Walter Benjamin or The Commodity as Phantasmagoria", New German Critique, n. 83, Spring - Summer 2001, p. 20). Sobre la "asfixia expresiva" que afecta al espacio público del siglo XIX véase Sennett, R., El declive del hombre público, Barcelona, Anagrama, 2011 (segunda parte). Charles Taylor ha extendido este diagnóstico hasta nuestro propio presente, que define como la "época de la autenticidad", en la que el 
Por eso el passage parisino, a la vez exterior e interior, calle y vivienda, le servía a Benjamin como el emblema perfecto de esta transformación de lo público en un ámbito de mutua exhibición individual.

Utilizando marcos conceptuales distintos - el modelo estético de la "apariencia" o el modelo teológico del fetichismo de la mercancía - Benjamin describe una única experiencia histórica: la sintonía emocional con un mundo dotado de un rostro humano, demasiado humano. El objetivo último del ensayo sobre la obra de arte residía precisamente en mostrar la analogía estructural que conecta dos épocas en apariencia tan distintas como los siglos XIX y XX, en tanto que pre y posthistoria del mismo "origen" 51 . Como antes en la mercancía o los passages, Benjamin reconoce ahora en el cine una abreviatura de los poderes mágicos liberados por la modernidad. El cine insufla una falsa interioridad al mundo social desencantado del siglo XX, por ejemplo, cuando desplaza la atención de la actividad al agente: lo importante en quien es filmado no es lo que hace sino la interioridad que expresa, no el qué sino el quién. Esto es especialmente visible en el caso del intérprete cinematográfico, cuya exposición a través del aparato crea la "estrella", una nueva "realidad aurática" en la que se hace sensible una presencia no sensible. Lo mismo sucede con el resto de figuras filmadas, como el deportista o el hombre político, que son apreciados socialmente no por sus acciones sino por su personalidad (el carácter o los valores morales que expresan en público). Sus apariciones públicas, filtradas por el aparato, adquieren el "encanto de la personalidad" 52 .

Para captar el mecanismo mediante el que el cine dota a la realidad de esta expresividad espuria, Benjamin nos invita a ver en él una muestra de la imitación llamada "apariencia". Como hemos visto, la "apariencia" es una imitación que no solo representa algo sino que al representar algo lo es. Pues bien, la representación cinematográfica lleva a cabo una imitación de este tipo, ya que no representa un evento para que sea exhibido sino que efectúa el evento que representa. La copia cinematográfica no se limita a re-producir un evento sino que al reproducirlo lo produce. En el cine, como en el símbolo teológico, representar es ser 53 . En este senti-

expresivismo de la subjetividad romántica se convierte en fenómeno de masas (La era secular, Barcelona, Gedisa, 2014, cap. 13).

51 Véanse las declaraciones explícitas de Benjamin al respecto, por ejemplo, en Gesammelte Briefe, Frankfurt am Main, Suhrkamp, 2000, vol. V, p. 190 (carta a Scholem del 24/10/35) y p. 209 (carta a Kraft del 27/12/35). En adelante citado como GB, seguido del número de volumen y página. Véase también GS V, 1, p. 585 (N6, 5).

52 GS VII, 1, p. 370.

53 En el sacramento de la eucaristía, la representación de la consagración de Cristo en la última cena efectúa lo que representa de forma figurada, es decir, hace que el espíritu divino se manifieste de nuevo en el pan y el vino de la misa. Giorgio Agamben ha observado que el "sacramento", a diferencia del signo convencional, es un signo que "efectúa aquello que figura" (Signatura rerum. Sul metodo, Torino, Bollati Boringhieri, 2008, pp. 45-48), sugiriendo además una conexión histórica entre los sacramentos y la "semejanza eficaz" con la que Mauss describe la mimesis mágica (pp. 53-55). 
do, el "valor de culto" del arte retoma el "carácter cultual" 54 que Benjamin asignaba a la tragedia en el libro sobre el Barroco. De hecho, la oposición entre la "ostentación" del Trauerspiel barroco y el "culto" de la tragedia griega puede verse como una prefiguración asombrosa de la polaridad entre arte expositivo y cultual.

El objetivo del Trauerspiel era ser exhibido ante un público, por lo que no estaba ligado a un único espacio (de ahí que empleara un "escenario itinerante" 55 , que podía reproducir la obra en diferentes lugares para diferentes espectadores). En cambio, la tragedia griega se representaba en un "teatro abierto" 56 , o sea, un escenario fijo en el que el espacio de la representación ya no es separable de la acción representada. La tragedia no se dirigía a la exhibición de la acción dramática sino a su ejecución: "no es una exhibición repetible (wiederholbare Ostentation) sino la reanudación única (einmalige Wiederaufnahme) del proceso trágico" 57.

Los dos modos de relación entre la acción (modelo) y su representación (copia) que Benjamin detectaba en el Trauerspiel y la tragedia - distancia o identificación, repetibilidad o unicidad 58 - definen de nuevo las dos funciones opuestas del arte en el siglo XX: exhibición y culto, juego y apariencia. La representación fílmica es, parafraseando las palabras de Benjamin sobre la tragedia, la "reanudación única del evento aurático", y en la época en que las masas hacen su aparición histórica, el evento aurático por excelencia es el "culto del público"59, es decir, la transfiguración de la masa en la encarnación empírica de un principio trascendente. Como el culto griego, la reproducción fílmica de la masa actualiza el evento que representa, es decir, insufla a la realidad el aura que su reproducción técnica evoca por medios sensibles. De esta forma, el modo de recepción de la obra de arte aurática (el "recogimiento"60 o el "abismarse contemplativo"61 del sujeto en la obra) es trasladado a

\footnotetext{
54 GS I, 1, p. 241.

55 GS I, 1, p. 298.

56 ibidem.
}

57 ibidem. Los mismos dos polos aparecen en el análisis de Johan Huizinga, para quien el juego es una "realización aparente" mientras que "el culto produce el efecto que en la acción se representa de modo figurado. Su función no es la de simple imitación, sino la de dar participación o la de participar" (Homo ludens, Madrid, Alianza, 2000, pp. 28-29). Aunque el objetivo de Huizinga era incluir el culto como subespecie del juego, vacila al encontrarse con la "identificación" o "unidad mística" que se da en el culto entre copia y modelo. El juego se basa en la conciencia de un distanciado hacer como si, mientras que el culto es impensable sin una "entrega absoluta" (p. 38). En su danza mágica el niño o el salvaje no juega a ser sino que "es" el animal que imita (p. 42). Este rasgo diferencial del culto es el que permite a Benjamin tratarlo no como una variante del juego sino como su polo opuesto.

58 No se trata solo de una oposición entre dos modos de representación dramática (repetible o única) sino también entre dos tipos de acontecimiento histórico: el Trauerspiel barroco es un acontecimiento repetible (por ejemplo, en el expresionismo del siglo XX) mientras que la tragedia griega es única y no puede actualizarse en el futuro (Fenves, P., Arresting language. From Leibniz to Benjamin, Stanford, Stanford University Press, 2001, p. 234).

59 GS VII, 1, p. 370.

60 GS VII, 1, p. 379. 
la recepción de la realidad exterior, que aparece como un espacio de comunicación directa entre dos interioridades (la del espectador y la que se expresa en la copia filmada de la realidad). Frente a la creciente disolución de los vínculos sociales, el cine ofrece al sujeto la inmersión compensatoria en un ser en común 62 .

En la exposición "dialéctica" de Benjamin la época aparece dividida en dos tendencias opuestas. La realidad, mediada técnicamente, se presenta bien como expresión de una interioridad (ser en común), bien como un catálogo de modelos impersonales de acción (hacer en común). En el "juego" la realidad representada técnicamente no aparece solo como la copia sensible de un modelo inteligible sino que es a la vez copia y modelo de futuras imitaciones. El juego es "un imitar cuyo interior oculto es un mostrar cómo se hace"63. Esta capacidad del cine para capturar el aspecto ejemplar de la realidad - en actividades que ejemplifican un modelo para la acción, el "cómo se hace" - es lo que Benjamin describe mediante el fenómeno del "test".

Bajo las condiciones técnicas prescritas por el cine, el trabajo del intérprete toma la forma de un "test de prestaciones" en el que no se trata ya de encarnar un personaje ideal (como hacía el actor teatral) sino de superar pruebas de rendimiento ante los aparatos de registro, es decir, de exhibir la destreza en la ejecución de una serie de acciones (que serán compuestas durante el montaje para producir sintéticamente la acción dramática). El trabajo del actor, por tanto, no consiste en expresar una identidad sino en imitar con habilidad un modelo impersonal de acción.

El cambio de función que Benjamin detecta en el actor de cine resalta con claridad al compararlo con la descripción que ofrece Georg Simmel en "El actor y la realidad" (1912). Como Benjamin, que define la mimesis como el "fenómeno originario" de la actividad artística, Simmel ve en el actor teatral el "fenómeno originario"64 de la actividad artística y, en general, de la actividad humana. El propósi-

61 ibidem.

62 El esbozo que Benjamin ofrece del uso cultual de la técnica por parte del fascismo podría completarse con el trabajo de Peter Reichel, quien ha realizado un amplio catálogo de los fenómenos de estetización en la Alemania de los años treinta (Der schöne Schein des dritten Reiches. Faszination und Gewalt des Faschismus, München, Hanser, 1991). Como Benjamin, Reichel ve el principio común de los diferentes dispositivos de fascinación de masas en la concepción de la obra de arte como "bella apariencia", es decir, la evocación por medios sensibles de una presencia no sensible. El orden superior del "ein Volk, ein Führer, ein Reich" toma cuerpo sensible, por ejemplo, en el orden geométrico y las coreografías al unísono de los acontecimientos de masas, que expresan de forma visible la voluntad única del Volk (pp. 205-213); en las reuniones del partido, donde el poder político se personifica en la figura del Führer, como abreviatura visible de la compleja máquina estatal (p. 146); o en la arquitectura monumental que muestra visiblemente el Reich como la reencarnación del esplendor imperial del pasado.

63 GS VII, 2, pp. 667-668.

64 Simmel, G., El individuo y la libertad, Barcelona, Península, 2001, pp. 313-314. 
to de Simmel en el ensayo era superar el dualismo entre naturalismo y expresionismo, es decir, la concepción de la interpretación actoral como una "imitación" o "calco mecánico" 65 del texto dramático o como la libre expresión de la individualidad del actor. El actor debe respetar el contenido de la obra pero, a la vez, debe conferirle una forma que vivifique su objetividad inerte. Así, al asignarle al actor la tarea de producir una "unidad orgánica" entre la ley objetiva y la ley subjetiva (el contenido y la forma), Simmel reúne ambas esferas en una nueva totalidad66. Aunque Benjamin pudiera en principio estar de acuerdo con el propósito simmeliano de superar la dicotomía entre ley objetiva y ley subjetiva - en tanto que dos modos diferentes del modo de imitación que denomina "apariencia" - su solución tenía que parecerle insuficiente, dado que la síntesis de contenido y forma (modelo y copia) permanece atrapada en el interior del esquema expresivístico que Benjamin pretendía superar.

La tarea del actor no es lograr una síntesis expresiva sino producir una acción imitable: dar concreción sensible a un modelo que, sin embargo, excede cada una de sus ejemplificaciones concretas, sin encontrar nunca una expresión definitiva, $y$, por ello mismo, exigiendo la invención de nuevas formas de traducirlo a términos empíricos. En todo caso, Benjamin, como Simmel, adopta el método goetheano del Urphänomen y expone la tarea del actor como ejemplo paradigmático del tipo de tareas a las que se enfrentan también el resto de hombres.

En un ambiente recubierto técnicamente las actividades de la vida cotidiana adoptan cada vez más la forma de un "test", la imitación de un modelo de acción, impuesto por el estándar técnico de los aparatos con los que nos relacionamos a diario: en el puesto de trabajo ("en las oficinas y en las fábricas"67), en la ciudad (como "transeúnte en el tráfico de la gran ciudad"68) o ante el resto de tareas que un paisaje hiperestimulado impone a la percepción sensible. Sin embargo, a diferencia de estas pruebas ante aparatos, aquella a la que se somete el actor presenta una peculiaridad: se puede exhibir ante un público. "El cine torna exhibible el test de prestación, haciendo un test de la propia capacidad de la prestación para ser exhibida"69. La imitación de un modelo, al ser exhibida, se convierte ella misma en modelo para la imitación de los espectadores. El cine ofrece al público un caso particular que es

65 ivi, p. 315.

66 Véase un análisis del ensayo en Valle, G., La vita individuale. L'estetica sociologica di Georg Simmel, Firenze, Firenze University Press, 2008, pp. 63-77. La obra de Simmel oscila entre dos polos opuestos: por un lado, el atomismo sociológico de sus primeros escritos, que analizan el conflicto trágico que opone en la modernidad a sujeto y objeto, y, por otro lado, la aspiración a una superación del conflicto en una totalidad superior que define su último periodo, marcado por el influjo de Goethe (Giacomoni, P., Classicità e frammento. Georg Simmel goethiano, Napoli, Guida, 1995, p. 32 y p. 45).

67 GS VII, 1, p. 365.

68 GS VII, 1, p. 380.

69 GS VII, 1, p. 365. 
a la vez un modelo general, aplicable a los distintos contextos donde es exhibido, en nuevas imitaciones o test ante la realidad técnica. Gracias al cine es posible exhibir públicamente la destreza específica que, hasta ahora, los hombres atesoraban de forma privada, en el contexto restringido donde desarrollaban su actividad. De esta manera, la acción experta se vuelve imitable: la negatividad del modelo, de la que el ejemplo es portador, puede trasladarse a nuevas situaciones empíricas. Cada uno de nosotros, como experto en el commercium con una determinada región del mundo técnico (como imitador diestro de un cierto modelo de acción) se convierte en un intérprete que muestra a los demás el modelo en el que es competente y, de esta manera, los coloca en la posición de "semi-especialistas"70, capaces no solo de apreciar la calidad de la ejecución o imitación sino también de ver en ella lo que excede el caso particular y puede trasladarse a sus propios contextos de uso. El "test de prestaciones" exhibe una acción en la que lo relevante no es la interioridad que expresa sino lo que en ella no alcanza expresión, el modelo potencialmente válido para un número indefinido de casos particulares.

La nueva función del cine, por tanto, consiste en poner a disposición pública estos modelos, invitando al público a experimentar con la relación flotante que existe entre la negatividad del modelo y su ejemplificación en variados contextos empíricos. El único modo de lograr el "equilibrio entre el hombre y los aparatos" 71 será mediante una generalización de la imitación, prolongando la imitación exhibida por el cine en nuevas imitaciones 72 .

\section{Políticas de la expresión}

Hemos visto con detalle la estrategia expositiva del ensayo, en la que la mimesis ocupa un lugar central como clave para descifrar las transformaciones ocurridas en ámbitos tan distintos como la técnica y el arte. Para resaltar la intencionalidad política que guía la teoría benjaminiana de la imitación mostraremos ahora su con-

\footnotetext{
70 GS VII, 1, p. 371.

71 GS VII, 1, p. 375.

72 Para comprender la significación positiva del "juego" no basta con una apelación genérica a su carácter experimental y abierto a la indeterminación sino que hay que atender al hecho de que Benjamin lo conciba como una forma de imitación. En las nuevas condiciones técnicas, la acción libre solo es posible como imitación de los ejemplos modélicos que pone a nuestra disposición la técnica de reproducción. El cine "expositivo" abre un Spielraum (GS VII, 1, p. 369) - indistintamente "campo de acción" y "campo de juego" - es decir, un margen para la imitación o traducción de la negatividad presente en el caso ejemplar a la concreción de nuevos ejemplos de acción. Para un análisis alternativo de la categoría de Spielraum véase Hansen, M. B., "Room-for-Play: Benjamin's Gamble with Cinema", October, 109, 2004, pp. 20-24.
} 
traste con los trabajos contemporáneos sobre la mimesis de Roger Caillois ${ }^{73}$. Aunque ambos autores recuperan la magia mimética para formular una crítica del presente, el uso opuesto que hace cada uno de ellos da lugar a dos diferentes politicas de la expresión.

Caillois emprende a mediados de los años treinta una investigación de "biología comparada"74 con la intención de aislar la "raíz común" de las diferentes manifestaciones del mimetismo. Una secreta correspondencia une a fenómenos tan heterogéneos como el mimetismo biológico (la tendencia de algunos seres vivos a asimilarse con el medio, a través de un cambio de color o de forma), el mimetismo mágico, la psicastenia (un desorden psíquico vinculado a la desorientación espacial) o determinadas expresiones literarias y artísticas. Caillois ve en estos fenómenos la manifestación de un instinto biológico dirigido a la "asimilación con el ambiente"75, la tendencia entrópica hacia la "uniformidad"76 del mundo inorgánico.

Ante fenómenos tan dispares (biológicos, psicológicos y sociales) Caillois emplea la mantis religiosa como principio guía de la investigación o, en sus propias palabras, como "ideograma objetivo que actualiza materialmente en el mundo externo las virtualidades de la afectividad"77. En las representaciones mitológicas de culturas y épocas independientes entre sí, Caillois observa el mismo motivo invariante: la presencia de criaturas femeninas que devoran a sus parejas masculinas. En la actitud mimética de la mantis, que se deja asimilar pasivamente a su pareja femenina, Caillois percibe una ilustración ejemplar de la tendencia general a la "reintegración en la insensibilidad originaria"78 que gobierna una gran variedad de formas de la imaginación, como mitos o narraciones. La mantis es "un mito en acto" 79 .

El análisis comparado de Caillois presenta una cierta afinidad con la descripción morfológica que Benjamin lleva a cabo, casi en paralelo, en el ensayo sobre la obra de arte. Si Benjamin define la mimesis como el "fenómeno originario" del arte, Caillois detecta en el mimetismo un "ideograma objetivo" de la superestructura cultural. El método de Caillois está basado en el "conocimiento por analogía", que indaga el principio de coherencia común a fenómenos causalmente independientes ${ }^{80}$. Sin embargo, en Caillois el influjo del conocimiento analógico procede del

\footnotetext{
73 "La mante religieuse" (1934) y "Mimétisme et Psychasthénie légendaire" (1935), ambos recogidos en Le mythe et l'homme (1938).

74 Caillois, R., "Mimétisme et Psychasthénie légendaire", p. 121.

75 ivi, p. 108.

76 ivi, p. 118.

77 Caillois, R., "La mante religieuse", p. 72.

78 ivi, p. 75.

79 ivi, p. 85.

80 Massonet, S., Les labyrinthes de l'imaginaire. Dans l'oeuvre de Roger Caillois, Paris, L'Harmattan, 1998, pp. 129-132.
} 
análisis estructural de Marcel Mauss ${ }^{81}$, y no de la morfología goetheana, como en Benjamin. El propio Caillois señala en otro lugar la distancia que separa su modelo de "ciencia diagonal" respecto al Urphänomen de Goethe, ya que aunque ambos buscan captar la unidad de los fenómenos, "su error [el de Goethe] estaba en buscarla por medio de los sentidos y primordialmente con la vista" 82 . Es decir, se trata de buscar "correspondencias funcionales" y no "semejanzas formales" 83 . Aun admitiendo esta salvedad, cabría preguntarse si la analogía "funcional" que Caillois describe entre el ámbito material de la zoología y el ámbito espiritual de la mitología (entre el insecto y el hombre) es sustancialmente distinta de la relación "formal" de "expresión" entre técnica y arte que Benjamin se propone mostrar mediante su exposición 84 .

En todo caso, la afinidad de método entre ambos no puede ocultar las profundas diferencias que los separan. En primer lugar, el análisis de Caillois conserva todavía un residuo "genético" que sobrepasa los límites de una descripción estrictamente morfológica ${ }^{85}$. El paralelismo entre el mimetismo instintivo y la actividad de la imaginación tiene un fundamento biológico, dado que el hombre no es una excepción en la naturaleza y "no escapa a las leyes biológicas"86. Para Benjamin, en cambio, el "fenómeno originario" es un instrumento de interpretación y no de explicación empírica (no hay que confundir el "origen" de los fenómenos con la "causa" o la "génesis"87).

La segunda diferencia no se debe tanto al método como a la orientación política que lo guía en cada caso. En el pensamiento de Caillois, al menos desde Le mythe et l'homme, la estructura de las formas culturales toma la forma de una contraposi-

\footnotetext{
81 ivi, pp. 122-125. Acerca de la influencia de Mauss sobre Caillois (así como sobre el Collège de Sociologie) véase Moebius, S., Marcel Mauss, Konstanz, UVK-Verlag, 2006, p. 39 ss.

82 Caillois, R., Medusa y Cía, Barcelona, Seix Barral, 1962, p. 16.

83 ivi, p. 138.

84 Benjamin parece reconocer una cierta afinidad metodológica con los ensayos de Caillois cuando disiente en parte de la posición de Adorno sobre el método de "La mantis religiosa". Por un lado Adorno valora positivamente el "materialismo" del ensayo, que reduce la superestructura cultural a una base natural y supera así el falso aislamiento mutuo (Briefwechsel 1928-1940, Frankfurt am Main, Suhrkamp, 1995, p. 277 [carta a Benjamin del 22/09/1937]). Pero, por otro lado, critica el "materialismo vulgar" de base biológica, que acaba eliminando el factor histórico-social (Adorno, T. W. Gesammelte Schriften, vol. 20, I, Frankfurt am Main, Suhrkamp, 1986, p. 230). Benjamin, en cambio, se muestra más ambivalente por lo que respecta al método de Caillois: "todavía no he decidido si realmente puede ser caracterizado como "materialismo vulgar"” (GB V, p. 581 [carta a Adorno del 02/10/1937]). En efecto, el refinado análisis comparado de Caillois difícilmente pudo haber escapado a la sensibilidad morfológica de Benjamin.

85 Sobre la oscilación de Caillois entre ambos niveles de discurso (la descripción de la homología hombre-naturaleza y la explicación evolutiva) véase Massonet, S., op. cit., pp. 113-114.

86 Caillois, R., "La mante religieuse", p. 82.

87 Sobre esta distinción véase, por ejemplo, GS I, 1, p. 226 y GS V, 1, p. 577 (N2a, 4).
} 
ción entre dos principios opuestos: distinción y asimilación, separación o identificación entre el yo y su ambiente88. También Benjamin describe los fenómenos del presente a partir de una polaridad de asimilación y distancia, Uno y Dos, pero esta polaridad es la imagen especular de la de Caillois. Mientras que Benjamin contrapone el reencantamiento mágico del mundo ("apariencia") a su desencantamiento ("juego"), en el análisis de Caillois los dos polos están invertidos: el momento de identidad mimética designa ahora el desencantado retorno a la indistinción originaria, y el momento de distancia hace referencia a la restauración de la diferencia entre lo inorgánico y lo orgánico. En otras palabras: si para Benjamin el mimetismo designa la unidad arcaica del mundo natural con un principio trascendente, para Caillois en cambio designa la moderna clausura en un orden cerrado y sin trascendencia. Por tanto, el mimetismo adquiere en ambos autores una valencia opuesta: el retorno de lo sagrado (Benjamin) o su disolución (Caillois).

De la divergente lectura del presente que ambos autores extraen del fenómeno de la mimesis se sigue un diseño diametralmente opuesto de las tareas políticas que el presente debe resolver: ya sea la liquidación de lo sagrado (Benjamin) o su restauración (Caillois). El Collège de Sociologie, del cual Caillois fue uno de los miembros fundadores, se propuso analizar la sociedad moderna en los términos empleados por autores como Durkheim o Mauss para estudiar las culturas primitivas (con categorías como el mito, lo sagrado o la mimesis). De acuerdo con esta motivación general, Caillois recurre al mimetismo para describir la homogeneización de la sociedad de masas de los años treinta. Y, consecuentemente, prescribe como lenitivo un retorno de lo sagrado 89 .

Caillois explora las consecuencias políticas de su reflexión sobre el mimetismo en Le Vent d'Hiver (1937), donde analiza la desintegración de la sociedad en átomos individuales (así como su contracara, la homogeneización en masa) en los términos de una tendencia a la indistinción con lo inorgánico. Una sociedad "que se ha profanado a sí misma"90 necesita reinstaurar aquel índice de exterioridad que Caillois denomina "lo sagrado" 91 . La recuperación de la alteridad pasa por producir un desnivel en el interior mismo de lo profano, por ejemplo, trazando una sepa-

\footnotetext{
88 Sobre la "lógica doble" que rige las antinomias de la imaginación en Caillois véase Massonet, S., op. cit., pp. 125-129.

${ }^{89} \mathrm{La}$ "indiferenciación" entre las esferas de lo religioso y lo político, uno de los objetivos principales del Collège, conduce a una "estetización de lo social" (Moebius, S., Der Zauberlehrlinge. Soziologiegeschichte des Collège de Sociologie (1937-1939), Konstanz, UVK-Verlag, 2006, p. 254 ss.). Es decir, precisamente el enemigo central de Benjamin en el ensayo.

90 Caillois, R., "The Winter Wind", en D. Hollier (ed.), The College of Sociology (1937-1939), Minneapolis, University of Minnesota Press, 1988, p. 36.

91 Se trata de "restaurar una asimetría jerárquica y revivir la diferencia entre diferencia y no-diferencia", entre sagrado y profano (Hollier, D., "Mimesis and Castration", October, vol. 31, Winter 1984, p. 12).
} 
ración en el seno de la sociedad entre dos grupos de hombres ${ }^{92}$ : aquellos capaces de dominarse a sí mismos y aquellos que permanecen sujetos a la satisfacción de sus instintos, asimilándose así a la naturaleza. En definitiva, los amos y los esclavos ${ }^{93}$. Es necesario diferenciar en el interior de la sociedad un grupo jerárquicamente superior, la comunidad sagrada, que por medio del autocontrol preserva la distinción del resto. El dominio y la desigualdad sociales son entonces necesarios como "fármaco anti-mimético"94.

El carácter regresivo de estas consideraciones no pasó inadvertido a Benjamin, que en su reseña sobre L'aridité denuncia la "praxis fascista" 95 a la que conducen las premisas de Caillois. En la restauración de la trascendencia, y no en su olvido, es donde Benjamin detecta el germen de la barbarie actual96. La mimesis como "apariencia" no coincide, por lo tanto, con el mimetismo descrito por Caillois sino más bien con su opuesto, lo sagrado. A la asimilación con la trascendencia, el volverse uno con lo Uno, Benjamin opone el otro polo de la mimesis, el juego, que introduce una distancia pero no con el mundo profano sino con la trascendencia que lo trasfigura ${ }^{97}$. Mientras Caillois va a buscar a un pasado remoto aquello que le falta

92 Caillois, R., "The Winter Wind", p. 37.

93 ivi, p. 39.

94 Hollier, D., "Mimesis and Castration", p. 13. El análisis de Caillois coincide en lo esencial con el de Bataille en "La estructura psicológica del fascismo" (1933), donde sostenía la necesidad de mantener la diferencia entre "lo homogéneo" y "lo heterogéneo" (La conjuración sagrada. Ensayos 19291939, Buenos Aires, Adriana Hidalgo, 2003, pp. 137-181). Paradójicamente, la potencia de lo heterogéneo solo puede surgir como resultado de una división practicada en el interior mismo de lo homogéneo, la inclusión de lo sagrado (Dos) solo se produce por medio de la exclusión de un parte de lo profano (Uno). Sobre la lógica de "inclusión excluyente" que gobierna el ensayo de Bataille véase Esposito, R., Due. La macchina della teologia politica e il posto del pensiero, Torino, Einaudi, 2013, pp. $48-54$.

95 GS III, pp. 549-550.

${ }^{96}$ A pesar de las estrechas relaciones que mantuvo con el Collège de Sociologie, Benjamin no se hacía ilusiones sobre las implicaciones políticas del pensamiento de sus amigos franceses. Como recuerda Klossowski en una nota retrospectiva, Benjamin pensaba que "bajo la apariencia de una absoluta incompatibilidad, corríamos el riesgo de hacer el juego a un "esteticismo prefascista"" ("Entre Marx et Fourier", en D. Hollier (ed.), op. cit., p. 389). Sobre las relaciones entre Benjamin y el Collège véase Miller, T., "Mimesis, Mimicry and Critical Theory in Exile. Walter Benjamin's Approach to the Collège de Sociologie", en E. Barkan (ed.), Borders, Exiles, Diasporas, Stanford, Stanford University Press, 1998, pp. 123-133.

97 El tipo de mimesis que Benjamin denomina juego no aparecerá en la obra de Caillois hasta más adelante, en Les Jeux et les hommes (1958), donde la mimicry (el hacer "como si") aparece como una de las cuatro especies del juego (junto a Agon, Alea e Ilinx). De esta manera, Caillois se distancia de su obra anterior, dado que el mimetismo no designa ya la sujeción a lo inorgánico sino una de las dimensiones de la libre creación humana. Contra la tesis de Huizinga, Caillois ve en el juego - el ámbito de la convención sin contenidos prefijados - lo opuesto al culto sagrado - la total subordinación a un contenido trascendente (L'homme et le sacré, Paris, Gallimard, 1950, pp. 211-216). Así, al situar el juego y lo sagrado en los dos extremos opuestos del rango de la actividad humana, Caillois se acaba acer- 
al presente, Benjamin describe la esencial ambigüedad del presente, en el que coexisten tendencias regresivas y progresivas, tanto un retorno del culto como su disolución expositiva. Dos posibilidades que, de acuerdo con el método de "investigación del origen", Benjamin encuentra preformadas en los dos lados de la mimesis, apariencia y juego.

\section{Conclusión}

Como hemos visto, el análisis de Benjamin sobre el destino del arte a principios del siglo XX estaba al servicio de una investigación más amplia sobre la estructura unitaria de la época. De esta manera, Benjamin intentaba mostrar la solidaridad oculta que vincula el empleo de la técnica, el régimen de percepción o la concepción del arte. Pero si el arte ha sido tradicionalmente considerado como el ámbito privilegiado de la creatividad humana, entonces la trasformación histórica de su función es el signo de una transformación que afecta al estatuto moderno de lo nuevo. En un momento histórico en el que la técnica se convierte en el primer motor de innovación, el hombre pierde la hegemonía de la espontaneidad ante sus propios productos y se ve sustituido en aquello que consideraba más propio, la facultad soberana de concebir y producir lo nuevo. Así como la irrupción de la subjetividad moderna había significado el ocaso del modelo antiguo de la imitación, Benjamin advierte a principios el siglo XX una nueva cesura histórica que empieza a volver obsoleto al yo soberano moderno. De hecho, como ya vimos, la imitación clásica y la expresividad moderna no eran para Benjamin más que dos caras de lo mismo, ya que ambas presuponían el mismo tipo de relación modelo-copia (la "apariencia"). En la obediencia a un modelo natural y en las fantasías de control sobre la naturaleza Benjamin detectaba la misma experiencia de participación con la realidad.

Frente a la "apariencia" Benjamin ve en el "juego" - el otro polo de la imitación - una oportunidad de salir del círculo mágico de la contemplación. Para afrontar los formidables retos que se le plantean al hombre ante un entorno drásticamente remodelado por la técnica, Benjamin propone recurrir a una imitación que toma la realidad a la vez como copia y como modelo de futuras copias. El "juego" explota la capacidad de la nueva técnica para mostrar la realidad en su aspecto ejemplar o imitable, es decir, aquel aspecto cuya percepción invita a prolongarlo en una nueva acción (a traducir la potencialidad del ejemplo particular en nuevas copias). Por tanto, el juego implica la contemplación "reproductiva" de algo dado, pero no para calcarlo en otra materia sino para captar lo que excede el caso particular y

cando a la oposición benjaminiana entre juego y apariencia. Para un punto de vista diferente sobre el contraste entre la concepción benjaminiana del juego y la de Caillois o Huizinga véase Hansen, M. B., "Room-for-Play", pp. 12-13. 
puede aplicarse de forma "creativa" a otras situaciones empíricas. No consiste en subsumir bajo una regla dada ni en plasmar la espontaneidad de un yo sino en inventar nuevos modos particulares de seguir una regla dada. La imitación, entendida a la manera del juego, es tanto reiteración de lo dado como creación autónoma. La tarea del hombre que habita en la época de la reproductibilidad técnica ya no es la de crear ex-nihilo lo nuevo sino la de "reconocer lo nuevo"98, captar en lo empírico aquello que está más allá de lo empírico pero, a la vez, permaneciendo sensible al contexto, según la peculiar dialéctica de distancia y contacto propia del juego. Esa tarea coincide entonces con la "vollendende Mimesis"99, literalmente, la "mimesis que completa" o "consuma", es decir, la acción que otorga realidad a la vida ideal percibida en los objetos y situaciones del mundo cotidiano.

\section{Bibliografía}

Adorno, T. W. / Benjamin, W., Briefwechsel 1928-1940 (hrsg. H. Lonitz), Frankfurt am Main, Suhrkamp, 1995.

Adorno, T. W., "Roger Caillois. La Mante religieuse", en Id., Gesammelte Schriften (hrsg. R. Tiedemann), Bd. 20-I, Frankfurt am Main, Suhrkamp, 1986, pp. 229-230.

Agamben, G., Signatura rerum. Sul metodo, Torino, Bollati Boringhieri, 2008.

Assmann, A. y J., "Air from other Planets Blowing", en H. U. Gumbrecht and M.

Marrinan (ed.), Mapping Benjamin. The work of art in the digital age, Stanford,

Stanford University Press, 2003, pp. 147-157.

BATAILLE, G., "La estructura psicológica del fascismo", en La conjuración sagrada.

Ensayos 1929-1939, Buenos Aires, Adriana Hidalgo, 2003, pp. 137-181.

Benjamin, W., Gesammelte Schriften (hrsg. R. Tiedemann und H.

Schweppenhäuser), I-VII Bände, Frankfurt am Main, Suhrkamp, 1972-1989.

Benjamin, W., Gesammelte Briefe (hrsg. C. Gödde und H. Lonitz), I-VI Bände,

Frankfurt am Main, Suhrkamp, 1995-2000.

CAILloIs, R., Le mythe et l'homme, Paris, Gallimard, 2012.

CAillois, R., Les Jeux et les hommes. Le masque et le vertige, Paris, Gallimard, 1967.

CAillois, R., Medusa y Cía. Pintura, camuflaje, disfraz y fascinación en la naturaleza y en el hombre, Barcelona, Seix Barral, 1962.

CAILlois, R., L'homme et le sacré, Paris, Gallimard, 1950.

Canetti, E., Masse und Macht, Hamburg, Claassen, 1960.

98 GS V, 1, p. 493 (K1a, 6).

99 GS VII, 2, p. 668. 
Delgado Rojo, J. L., "Benjamin y Wittgenstein. Una aproximación morfológica", Ágora. Papeles de Filosofía, Vol. 34, No. 1, 2015, pp. 33-57.

Desideri, F., "I Modern Times di Benjamin", en Id. (ed.), L'opera d'arte nell'epoca della sua riproducibilità tecnica. Tre versioni (1936-39), Roma, Donzelli, 2012, pp. VII-XLV.

Desideri, F., "The mimetic bond: Benjamin and the question of technology", en A. Benjamin (ed.), Walter Benjamin and Art, London, Continuum, 2005, pp. 108120.

Esposito, R., Due. La macchina della teologia politica e il posto del pensiero, Torino, Einaudi, 2013.

Fenves, P., Arresting language. From Leibniz to Benjamin, Stanford, Stanford University Press, 2001.

FÜRNKÄs, J., "Aura”, en M. Opitz und E. Wizisla (hrsg.), Benjamins Begriffe. Bd. I, Frankfurt am Main, Suhrkamp, 2000, pp. 95-146.

Gehlen, A., "Die Seele im technischen Zeitalter", en Gesamtausgabe. Band 6, Frankfurt am Main, Klostermann, 2004, pp. 1-137.

Giacomoni, P., Classicità e frammento. Georg Simmel goethiano, Napoli, Guida, 1995.

Goethe, J. W., Goethes Werke. Hamburger Ausgabe. Bd XIII, Hamburg, Wegner, 1960.

Gomà LANZÓn, J., Imitación y experiencia, Barcelona, Crítica, 2005.

Hansen, M. B., Cinema and experience. Siegfried Kracauer, Walter Benjamin and Theodor W. Adorno, Berkeley, University of California Press, 2012.

Hansen, M. B., "Room-for-Play: Benjamin's Gamble with Cinema", October, 109, 2004, pp. 3-45.

Hollier, D. (ed.), The College of Sociology (1937-1939), Minneapolis, University of Minnesota Press, 1988.

Hollier, D., "Mimesis and Castration", October, vol. 31, Winter 1984, pp. 3-15.

Huizinga, J., Homo ludens. El juego y la cultura, Madrid, Alianza, 2000.

LANG, T., Mimetisches oder semiologisches Vermögen? Studien zu Walter Benjamins Begriff der Mimesis, Göttingen, Vandenhoeck \& Ruprecht, 1998.

LinDNER, B., "Das Kunstwerk im Zeitalter seiner technischen Reproduzierbarkeit", en Id. (hrsg.), Benjamin Handbuch. Leben - Werk - Wirkung, Stuttgart, Metzler, 2011, pp. 229-251.

Lindner, B., "Benjamins Aurakonzeption: Anthropologie und Technik, Bild und Text", en U. Steiner (hrsg.), Walter Benjamin 1892 - 1940. Zum 100. Geburtstag, Bern, Lang, 1992, pp. 217-248.

Markus, G., "Walter Benjamin or The Commodity as Phantasmagoria", New German Critique, n. 83, Spring - Summer 2001, pp. 3- 42. 
Massonet, S., Les labyrinthes de l'imaginaire. Dans l'oeuvre de Roger Caillois, Paris, L'Harmattan, 1998.

Mauss, M., "Esbozo de una teoría general de la magia", en Sociología y Antropología, Madrid, Tecnos, 1979, pp. 45-152.

Menninghaus, W., "Das Ausdrucklose: Walter Benjamins Metamorphosen der Bilderlosigkeit", en I. und K. Scheuerman (hrsg.), Für Walter Benjamin. Dokumente, Essays und ein Entwurf, Frankfurt am Main, Suhrkamp, 1992, pp. 170-182.

Menninghaus, W., Walter Benjamins Theorie der Sprachmagie, Frankfurt am Main, Suhrkamp, 1980.

Miller, T., "Mimesis, Mimicry and Critical Theory in Exile. Walter Benjamin's Approach to the Collège de Sociologie", en E. Barkan (ed.), Borders, Exiles, Diasporas, Stanford, Stanford University Press, 1998, pp. 123-133.

Moebius, S., Der Zauberlehrlinge. Soziologiegeschichte des Collège de Sociologie (1937-1939), Konstanz, UVK-Verlag, 2006.

Moebius, S., Marcel Mauss, Konstanz, UVK-Verlag, 2006.

Mosès, S., "Walter Benjamin et le romantisme allemand", Europe, n. 1008, avril 2013, pp. 57-68.

Mosès, S., "L'idée d'origine chez Walter Benjamin", en H. Wismann (ed.), Walter Benjamin et Paris. Colloque international 27-29 juin 1983, Paris, Éditions du Cerf, 1986, pp. 809-826.

PinotTi, A., "'Lo studio degli stremi'. Benjamin morfologo tra Warburg e Goethe", en Id. (ed.), Giochi per melanconici. Sull' 'Origine del dramma barocco tedesco'di Walter Benjamin, Milano, Mimesis, 2003, pp. 195-231.

REICHEL, P., Der schöne Schein des dritten Reiches. Faszination und Gewalt des Faschismus, München, Hanser, 1991.

SchwePpenhäUser, H., "Zur Physiognomie eines Physiognomikers", en S. Unseld (hrsg.), Zur Aktualität Walter Benjamins, Frankfurt am Main, Suhrkamp, 1972.

SENNETT, R., El declive del hombre público, Barcelona, Anagrama, 2011.

Simmel, G., "El actor y la realidad", en El individuo y la libertad. Ensayos de crítica de cultura, Barcelona, Península, 2001, pp. 305-316.

Stoessel, M., Aura. Das vergessene Menschliche, München, Hanser, 1983.

TAYLOR, Ch., La era secular, Barcelona, Gedisa, 2014.

Valle, G., La vita individuale. L'estetica sociologica di Georg Simmel, Firenze, Firenze University Press, 2008.

José Luis Delgado Rojo

Scuola Normale Superiore (Pisa - Firenze)

jluisdelgado@hotmail.com 